PAULO FERNANDO SPELLING

\title{
Avaliação do sistema osteoprotegerina e RANKL em pacientes com artrite idiopática juvenil de início poliarticular
}

Tese apresentada à Faculdade de Medicina da Universidade de São Paulo, para obtenção do título de Doutor em Ciências.

Área de Concentração: Reumatologia

Orientador: Profa. Dra. Rosa Maria Rodrigues Pereira

São Paulo

2008 
Dados Internacionais de Catalogação na Publicação (CIP)

Preparada pela Biblioteca da

Faculdade de Medicina da Universidade de São Paulo

Oreprodução autorizada pelo autor

Spelling, Paulo Fernando

Avaliação do sistema osteoprotegerina e RANKL em pacientes com artrite idiopática juvenil de início poliarticular / Paulo Fernando Spelling. -- São Paulo, 2008.

Tese(doutorado)--Faculdade de Medicina da Universidade de São Paulo. Departamento de Clinica Médica.

Área de concentração: Reumatologia.

Orientadora: Rosa Maria Rodrigues Pereira.

Descritores: 1.Artrite reumatóide juvenil 2.Osteoprotegerina 3.Osso e Ossos/metabolismo 4.Inflamação 5.Marcadores biológicos

USP/FM/SBD-017/08 


\section{AGRADECI MENTOS}

Aos meus pais pelos exemplos de vida

Aos meus sogros pelo apoio e estímulo

À minha esposa e filhos pela compreensão e apoio

À minha filha Natali pelo auxilio científico e trabalho árduo de informática

À Profa. Dra. Rosa Maria Rodrigues Pereira pela orientação e paciência

Às colegas Valéria e Liliam pelo auxílio e orientação laboratorial

À Dra Wanda Bastos pelo contínuo incentivo à carreira científica e formação em reumatologia pediátrica

Aos funcionários do Laboratório de Análises do Hospital Evangélico de Curitiba, em especial à Soninha, pela colaboração na coleta de material. 


\section{SUMÁRIO}

Resumo

Summary

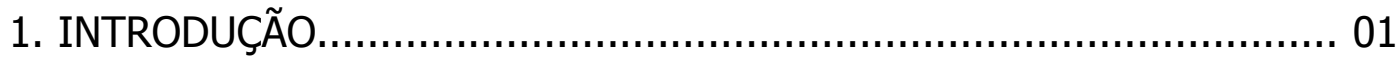

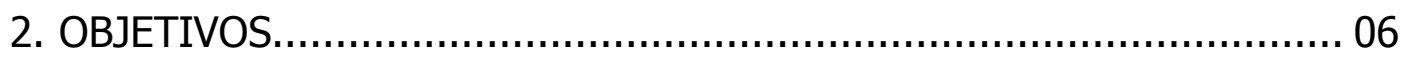

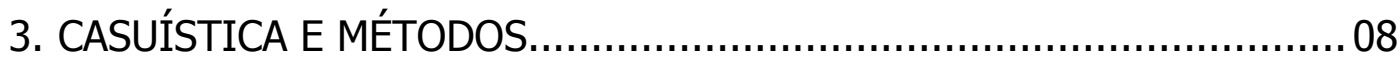

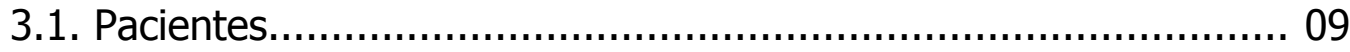

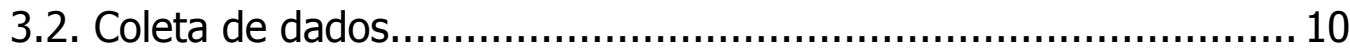

3.3. Envovimento articular, atividade articular e escore de atividade da doença (DAS) ..............................................................

3.4. Avaliação da classe funcional e qualidade de vida........................11

3.5. Avaliação radiológica............................................................. 11

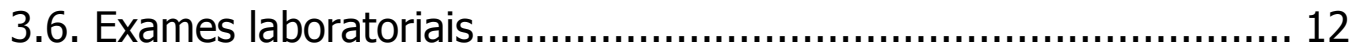

3.7. Análise estatística.................................................................. 13

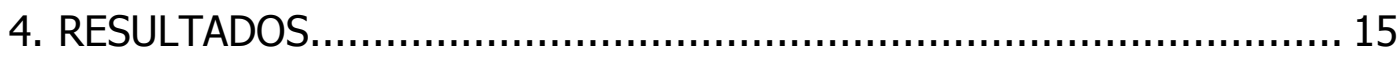

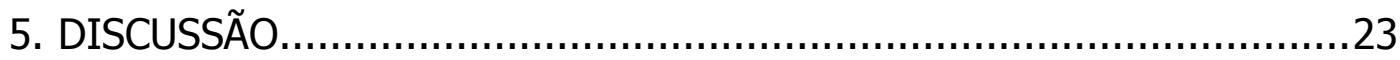

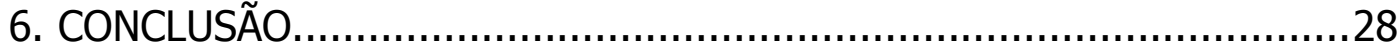

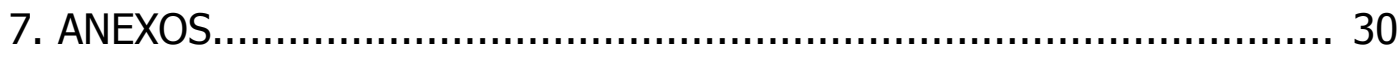

Anexo 1 - Artigo original........................................................... 31

Anexo 2 - Aprovação do projeto pela Comissão de Ética para

Análise de Projetos de Pesquisa do Hospital das

Clínicas da Faculdade de Medicina da USP....................... 56

Anexo 3 - Aprovação do projeto pelo Comitê em Pesquisa da

Sociedade Evangélica Beneficente de Curitiba.................... 57

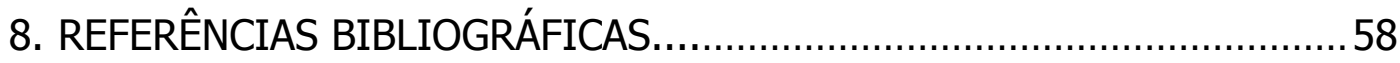




\section{RESUMO}

Spelling PF. Avaliação do sistema osteoprotegerina e RANKL em pacientes com artrite idiopática juvenil de início poliarticular [tese]. São Paulo: Faculdade de Medicina, Universidade de São Paulo. 2008. 65p.

OBJETIVO: Determinar os valores séricos do ligante do receptor do ativador do fator nuclear Kappa B (RANKL) e da osteoprotegerina (OPG) em pacientes com Artrite Idiopática Juvenil de início poliarticular (AIJp) em atividade e avaliar a possível correlação destes valores com a presença radiológica de erosões ósseas. MÉTODOS: Trinta pacientes do sexo feminino com diagnóstico de AIJ de início poliarticular segundo os critérios da ILAR (International League of Associations for Rheumatology) em atividade e trinta crianças saudáveis (controles) pareadas por idade e sexo foram selecionadas consecutivamente para este estudo. Todas as articulações comprometidas foram radiografadas e avaliadas, com especial interesse, para a presença de erosões ósseas. Concentrações séricas do RANKL e OPG foram medidas por enzima-imunoensaio (Biomedica, Vienna, Austria). RESULTADOS: Pacientes com AIJp em atividade apresentaram altos valores séricos de RANKL e menores taxas de OPG/RANKL comparadas com controles $[2,90(0,1-37,4)$ vs. $0,25(0,1-5,7) \mathrm{pg} / \mathrm{ml}, \mathrm{p}=0,007$ e $21,25(1,8-$ $897,6)$ vs. $347,5(9-947,8)] \mathrm{pg} / \mathrm{ml}, \mathrm{p}=0,005)$. Diferentemente, não houve diferença em relação à concentração sérica de OPG quando se comparou os pacientes e controles $[55,24(28,34-89,76)$ vs. $64,42(30,68-111,28) \mathrm{pg} / \mathrm{ml}$, $\mathrm{p}=0,256]$. Maiores concentrações de RANKL e menores taxas de OPG/RANKL também foram observadas em pacientes com AIJp em atividade com erosões ósseas comparadas com controles $[3,49(0,1-37,4)$ vs. $0,25(0,1-5,7) \mathrm{pg} / \mathrm{ml}$, $p=0,0115$ e $14,3(1,8-897.6)$ vs. $347,5(9-947,8) p=0,016]$. Em contraste, valores séricos de RANKL e a taxa de OPG/RANKL foram semelhantes em pacientes com AIJp sem erosões ósseas comparadas com controles [1,75 $(0,1-10,9)$ vs $0,25(0,1-5,7) \mathrm{pg} / \mathrm{ml}, \mathrm{p}=0,055$ e $29,2(3,3-756,8)$ vs. 347,5 (9$947,8), p=0,281]$. CONCLUSÃO: Estes dados sugerem que pacientes com AIJp em atividade com erosões ósseas apresentam altos valores séricos de RANKL e baixa taxa de OPG/RANKL indicando que estas alterações podem refletir o comprometimento ósseo nesta doença.

Descritores: 1. Artrite reumatóide juvenil 2. Osteoprotegerina 3. Osso e Ossos/metabolismo 4. Inflamação 5. Marcadores biológicos. 


\section{SUMMARY}

Spelling PF. Osteoprotegerin and RANKL system in patients with polyarticular-onset juvenile idiopathic arthritis [thesis]. São Paulo: Faculdade de Medicina, Universidade de São Paulo. 2008. 65p.

OBJECTIVE: To determine the serum levels of receptor activator of nuclear factor kB-ligand (RANKL) and osteoprotegerin (OPG) in active polyarticularonset Juvenile Idiopathic Arthritis patients (pJIA) and evaluate its possible correlation with bone erosions on the X-ray. METHODS: Thirty female girls with active pJIA diagnosis according ILAR criteria (International League of Associations for Rheumatology) and 30 healthy children gender and agematched controls were consecutively selected for this study. All involved articulations were evaluated by X-ray and analyzed for the presence of bone erosions. The serum levels of RANKL and OPG were measured using an enzyme-linked immunosorbent (Biomedica, Vienna, Austria). RESULTS: Results: Patients with active pJIA had higher levels of serum RANKL and lower OPG/RANKL ratio compared to controls [2.90 (0.1-37.4) vs. 0.25 (0.15.7) $\mathrm{pg} / \mathrm{ml}, \mathrm{p}=0.007]$ and $21.25(1.8-897.6)$ vs. $347.5(9-947.8) \mathrm{pg} / \mathrm{ml}$, $\mathrm{p}=0.005]$. However, levels of OPG were comparable in both groups [55.24 (28.34-89.76) vs. $64.42(30.68-111.28) \mathrm{pg} / \mathrm{ml}, \mathrm{p}=0.256]$. Higher levels of serum RANKL and lower OPG/RANKL ratio was also observed in active pJIA patients with bone erosions compared to controls [3.49 (0.1-37.4) vs. 0.25 (0.1-5.7) $\mathrm{pg} / \mathrm{ml}, \mathrm{p}=0.0115$ and 14.3 (1.8-897.6) vs. 347.5 (9-947.8), $p=0.016]$. In contrast, RANKL levels and OPG/RANKL ratio were alike in pJIA patients without bone erosion and controls $[1.75(0.1-10.9)$ vs. 0.25 (0.15.7) $\mathrm{pg} / \mathrm{ml}, \mathrm{p}=0.055$ and 29.2 (3.3-756.8) vs. 347.5 (9-947.8), $\mathrm{p}=0.281]$. CONCLUSION: These data suggest that active pJIA with bone erosion is associated with high serum levels of RANKL and low OPG/RANKL ratio indicating that these alterations may reflect bone damage in this disease.

Descriptors: 1. Juvenile rheumatoid arthritis 2. Osteoprotegerin 3. Bone and bones/metabolism 4. Inflammation 5. Biological markers 
1. INTRODUÇÃO 
Entre as patologias que ocorrem nas articulações, a artrite reumatóide é uma das mais freqüentes, podendo ocorrer na primeira infância, sendo denominada artrite reumatóide juvenil ou mais recentemente artrite idiopática juvenil (AIJ) (Cassidy JT, 2001; Petty et al, 2004).

Embora não haja diferença significativa no aspecto anátomopatológico entre a artrite reumatóide que ocorre no adulto e a AIJ, algumas diferenças clínicas são encontradas: os surtos febris constantes, o rash cutâneo, a tendência ao comprometimento de grandes articulações, o aparecimento de lesões oculares sérias e a soro-negatividade quase constante.

O termo AIJ abrange sete apresentações clinicamente distintas com um ponto em comum: a ocorrência de artrite crônica nas articulações sinoviais em crianças menores que 16 anos, cujo diagnóstico é estabelecido segundo os critérios da ILAR (International League of Associations for Rheumatology) (Petty et al, 2004).

O tipo de início poliarticular é o segundo em freqüência, respondendo por 30\% dos casos (Cassidy JT, 2001). Caracteriza-se pelo acometimento de cinco ou mais articulações, e as meninas são predominantemente afetadas. A artrite é geralmente simétrica, aditiva, acometendo pequenas e grandes articulações, além da coluna cervical e articulações temporo-mandibulares (Brewer et al, 1977; Ronchezel et al, 1995). Contraturas em flexão, fraqueza 
e dificuldade de deambulação são típicas. Erosões ósseas e destruição articular são freqüentes, podendo resultar em incapacidade articular grave necessitando de prótese articular. Osteopenia ocorre com freqüência, mesmo nos casos sem uso prévio de corticosteróide.

Durante a última década, o fator de necrose tumoral (TNF) foi identificado como o principal mediador inflamatório patogênico na artrite reumatóide capaz de induzir e propagar um processo inflamatório crônico na membrana sinovial (Vervordeldonk \& Tak, 2002).

Pertencente à família do fator de necrose tumoral encontra-se uma tríade de citocinas que interferem no sistema imune, no metabolismo ósseo e nas funções endócrinas. São elas: RANKL - ligante do receptor do ativador do fator nuclear Kappa B (NF-KB); RANK - receptor do ativador do NF-KB e Osteoprotegerina (OPG)- receptor solúvel que inativa o RANKL (Hofbauer et al, 2001; Bezerra et al, 2005).

O RANKL é produzido por células da linhagem osteoblástica, linfócitos T ativados e sinoviócitos; e, estimula seu receptor RANK localizado em células dendríticas e osteoblastos, levando à diferenciação e aumento da sobrevida dos osteoclastos, além de aumentar a sobrevida e imunoestimulação das células dendríticas. A osteoprotegerina, proteína solúvel sintetizada pelos osteoblastos, age como um receptor competitivo ligando-se ao RANKL e assim impede a sua ligação ao RANK, diminuindo a ação dos osteoclastos (Hofbauer et al, 2001; Pereira \& Pereira, 2004; Bezerra et al, 2005). 
O sistema RANKL/RANK/OPG é implicado em várias doenças imunológicas e esqueléticas caracterizadas por reabsorção óssea incluindo osteoporose pós-menopausa, osteoporose induzida por corticosteróides, metástases ósseas, doença periodontal e artrites inflamatórias (Lerner UH, 2004; Teng et al, 2000). De fato, a literatura e nós demonstramos que o processo inflamatório crônico resulta na perda de massa óssea generalizada, desmineralização óssea e alterações radiológicas características e progressivas (Pereira et al, 1998; Reed et al, 1991; Mason et al, 2002). As complicações ósteo-articulares consistem de osteopenia justa-articular, cistos ósseos, erosões ósseas marginais e subcondrais levando a deformidades e incapacidade física.

Reforçando estes achados, RNA mensageiro e proteínas do RANKL são expressos e produzidos por fibroblastos sinoviais e linfócitos $T$ ativados nas articulações artriticas de ratos com artrite induzida por adjuvante (AA). Esta artrite experimental é caracterizada pelar perda óssea e destruição articular devido ao aumento de reabsorção óssea refletindo um aumento do número de osteoclastos. Além disso, células T ativadas CD4+ e CD8+ expressam formas biologicamente ativas de RANKL solúvel e ligadas a membrana (Kong et al, 1999).

Interessantemente, o tratamento de animais com artrite induzida por adjuvante com OPG recombinante protege contra o desenvolvimento da destruição óssea e articular. Este efeito poupador ósseo ocorre mesmo se o tratamento com OPG não modifique o processo inflamatório sinovial (Kong et 
al, 1999). Estes dados sugerem, portanto que RANKL é essencial para a osteclastogênese e pode desta maneira modular a reabsorção óssea independente do processo inflamatório.

No presente estudo, avaliamos pacientes com AIJ tipo poliarticular, uniformemente ativos (para homogenizar esta variável inflamatória de confusão) com e sem erosão óssea, no sentido de entender a relevância do sistema RANK/RANKL/OPG na modulação da lesão óssea nesta doença. 
2. OBJ ETI VOS 
1- Determinar os valores séricos do ligante do receptor do ativador do fator nuclear Kappa B (RANKL), da osteoprotegerina (OPG) e da relação OPG/RANKL em pacientes com AIJ de início poliarticular em atividade e comparar essas variáveis com as de crianças saudáveis pareadas por idade e sexo.

2- Correlacionar os valores de RANKL, OPG, OPG/RANKL com a presença de erosões ósseas ao raios- $X$ nestes pacientes. 
3. CASUÍ STI CA E MÉTODOS 


\subsection{Pacientes}

Trinta pacientes do sexo feminino com diagnóstico de Artrite Idiopática Juvenil (AIJ) de início poliarticular segundo os critérios da ILAR (International League of Associations for Rheumatology) (Petty et al, 2004) em atividade foram selecionadas consecutivamente para o estudo. 0 principal critério de inclusão foi doença ativa, definida pelo escore de atividade de doença (DAS) (Lurati et al, 2006) maior do que 2,4. Todos os pacientes eram acompanhados no Serviço de Reumatologia Pediátrica do Departamento de Pediatria do Hospital Evangélico de Curitiba da Faculdade Evangélica de Curitiba.

Trinta crianças e/ou adolescentes saudáveis, pareadas por idade e sexo em relação aos pacientes, e do mesmo meio sócio-econômico, foram recrutadas como controles.

\section{Critérios de exclusão}

1. Doenças ósteo-metabólicas associadas (raquitismo, hipoparatiroidismo, etc.) 
2. Doenças crônicas associadas (diabetes, insuficiência renal ou hepática, hipertiroidismo ou hipotiroidismo, má-absorção).

3. Uso de glicocorticóide por pelo menos um (1) mês antes da coleta.

\subsection{Coleta de dados}

Dados demográficos e antropométricos foram obtidos por entrevista e exame físico nas pacientes e controles: idade em anos, peso em $\mathrm{Kg}$, altura em centímetros, estadio puberal de Tanner (Tanner JM, 1962) e idade da menarca em anos.

Dados clínicos incluindo duração de doença, número de articulações acometidas e ativas, incapacidade de doença, uso de glicocorticóide prévio, uso de metotrexato foram obtidos através de revisão de prontuário, entrevista e exame físico.

\subsection{Envolvimento articular, atividade articular e escore de atividade da doença (DAS)}

O envolvimento articular foi definido como a somatória de todas as articulações acometidas (edema, dor à palpação ou movimentação e limitação de movimento). O número de articulações ativas foi definido como a presença de edema ou limitação, associado(s) à presença de dor à movimentação ou palpação (van Rossum et al, 2003). 
Atividade da doença foi avaliada pelo escore de atividade de doença (DAS) (Lurati et al, 2006), onde o escore maior do que 2,4 foi considerado como indicativo de doença ativa.

\subsection{Avaliação de classe funcional e qualidade de vida}

Nos pacientes com AIJ a classe funcional foi avaliada pelo critério de Steinbrocker (Steinbrocker, 1969) e a qualidade de vida pelo CHAQ (Childhood Healthy Questionnaire) (Brasil et al, 2003), que avalia a condição atual do paciente segundo ele mesmo ou seu cuidador direto.

\subsection{Avaliação Radiológica}

Radiografia convencional de todas as articulações afetadas foram obtidas com especial interesse pelo raios-X de mãos e punhos. Foram avaliadas as seguintes alterações: 1 . presença de edema de partes moles, 2 . presença de osteopenia periarticular, 3. presença de diminuição de espaço articular, 4. presença de cistos e erosões ósseas (Mason et al, 2002, van Rossum et al, 2003).

Alta intensidade de luz foi utilizada para avaliar a presença de edema de partes moles. Osteopenia subcondral foi considerada presente quando uma densidade óssea diminuída foi observada na região periarticular. Erosão óssea foi definida como uma interrupção da superfície cortical do osso.

A análise radiográfica foi feita pela concordância do laudo de dois médicos experientes na avaliação do sistema músculo esquelético. 


\subsection{Exames laboratoriais}

\section{Dosagem de RANKL e Osteoprotegerina}

O soro para medida do RANKL (ligante do receptor do ativador do fator nuclear Kappa B), OPG (osteoprotegerina) dos pacientes e controles foram coletados em jejum e estocados a $-80^{\circ} \mathrm{C}$ para posterior análise no Laboratório de Metabolismo Ósseo da Disciplina de Reumatologia da FMUSP (LIM-17).

As concentrações séricas de RANKL não complexado (livre) foram determinadas através de técnica de ELISA (Biomédica, Viena, Áustria) seguindo orientações do fabricante. $\mathrm{O}$ soro e anticorpo biotinilado antiRANKL solúvel foram adicionados aos poços da placa. RANKL humano, se presente na amostra, compete na ligação com a OPG recombinante aderida à placa, formando um complexo tipo sanduíche. Após o período de incubação, o substrato tetrametil-benzidina (TMB) é adicionado como substrato para deteç̧ão. A leitura foi realizada em leitor de ELISA a $450 \mathrm{~nm}$. O coeficiente de variação intra e inter-ensaio em nosso Laboratório foi de $11,8 \%$ e $19,45 \%$, respectivamente (Bezerra et al, 2005).

Os níveis séricos de OPG foram determinados usando técnica de ELISA tipo sanduíche (Biomédica, Viena, Áustria) seguindo orientações do fabricante. A metodologia utiliza anticorpo monoclonal anti-OPG aderido à placa para capturar a OPG no soro. A OPG capturada foi detectada adicionando um segundo anticorpo policlonal anti-OPG conjudado a biotina, 
e foi detectada através da estreptavidina-peroxidade e substrato tetrametilbenzidina (TMB). A leitura foi realizada em leitor de ELISA a $450 \mathrm{~nm}$. O coeficiente de variação intra e inter-ensaio em nosso Laboratório foi de 5,2\% e $15,5 \%$, respectivamente (Bezerra et al, 2005).

\section{Velocidade de Hemossedimentação e Fator Reumatóide}

A velocidade de hemossedimentação (VHS) e dosagem de fator reumatóide (FR) foram realizados em todos os pacientes pela rotina no Laboratório Central do Hospital Evangélico de Curitiba da Faculdade Evangélica de Curitiba. A VHS foi considerada alterada quando acima de 20 $\mathrm{mm} / 1^{\mathrm{a}}$ hora e o FR positivo acima de $40 \mathrm{U}$.

Este estudo foi aprovado pela Comissão de Ética do Hospital das Clínicas da FMUSP (CAPPesq 948/06) e Comitê de Ética em pesquisa da Sociedade Evangélica Beneficiente de Curitiba (009/03).

\subsection{Análise Estatística}

Dados numéricos foram descritos como média e desvio padrão, mediana ou porcentagem.

Variáveis antropométricas e demográficas foram comparadas entre pacientes e controles utilizando-se o teste t-student. As variáveis estadio de Tanner $\geq M 2$, percentil de peso $\leq 25$, percentil de altura $\leq 25$ foram 
comparadas entre pacientes e controles usando o teste exato de Fisher. Níveis séricos de RANKL, OPG, OPG/RANKL foram comparados em pacientes com AIJ e controles através do teste não paramétrico de Mann-Whitney.

O teste Mann-Whitney também foi utilizado para comparar a presença ou ausência de erosões óssea com valores séricos de RANKL, OPG, tempo de doença, parâmetros clínicos (CHAQ, classe funcional, DAS, articulações acometidas e ativas) e parâmetros laboratoriais.

Os testes foram considerados significantes quando $p<0,05$. Todas as análises estatísticas foram realizadas utilizando-se SPSS Windows, versão 11,0 (SSPC, Chicago, IL). 
4. RESULTADOS 
As características demográficas e antropométricas das pacientes e controles são mostradas na tabela 1. A média de idade no momento do estudo das pacientes e controles foi de 11,07 anos $(p=1,00)$. Não houve diferença nos dados antropométricos, entre pacientes e controles, em relação a peso e altura $(p>0,05)$, no entanto, $40 \%$ dos pacientes com AIJp estavam abaixo do percentil 25 em relação ao peso, em comparação com $10 \%$ do grupo controle $(p=0,015)$. Semelhantemente, $93,3 \%$ das AIJ e $33,3 \%$ do grupo controle apresentavam percentil $<25$ em relação à altura $(p<0,0001)$. Em relação ao estadio puberal de Tanner, $93,3 \%$ das pacientes e $76,6 \%$ do grupo controle eram púberes (apresentavam estadios M2P2, M3P3, M4P4, M5P5) $(p=0,145)$.

O tempo médio de duração da doença foi $48,73 \pm 41,24$ meses. Quanto à classe funcional de Steinbrocker, a média nos pacientes foi de 1,7 $\pm 0,75$. A avaliação subjetiva do estado de saúde do paciente segundo o questionário na CHAQ foi de 1,46 \pm 0,87 e a média DAS foi de 4,71 $\pm 1,24$. A rigidez matinal variou de 0 a 60 minutos com uma média de $24,50 \pm 17,14$ minutos e a média da escala visual analógica da dor foi de $56,0 \pm 19,40$. 0 número de articulações comprometidas no momento do estudo variou de 5 a 55 articulações, com uma média de $21,27 \pm 11,96$, e a média das articulações ativas foi de 20,76 $\pm 11,73$ (tabela 2). 
Em relação à terapêutica no momento do estudo, $83 \%$ dos pacientes estavam usando metotrexato, 73,3\% anti-inflamatório não hormonal e 6,6\% azatioprina.

O fator reumatóide foi positivo em apenas $10 \%$ dos casos de AIJ e a média da velocidade de hemossedimentação foi de $44,47 \pm 27,53 \mathrm{~mm}$ na primeira hora.

Tabela 1 - Características demográficas e antropométricas em pacientes com Artrite Idiopática Juvenil de início poliarticular (AIJp) e controles saudáveis.

\begin{tabular}{lccc}
\hline & $\begin{array}{c}\text { AIJp } \\
(\mathrm{n}=30)\end{array}$ & $\begin{array}{c}\text { Controles } \\
(\mathrm{n}=30)\end{array}$ & $\mathrm{P}$ \\
& $11,07 \pm 3,77$ & $11,07 \pm 3,77$ & 1,00 \\
\hline Idade (anos) & $36,7 \pm 12,39$ & $43,75 \pm 16,82$ & 0,070 \\
Peso $(\mathrm{kg})$ & 40 & 10 & 0,015 \\
Peso $<25$ percentil, (\%) & $1,33 \pm 0,17$ & $1,43 \pm 0,18$ & 0,06 \\
Altura $(\mathrm{cm})$ & 93,3 & 33,3 & $<0,0001$ \\
Altura $<25$ percentil, (\%) & $19,89 \pm 3,15$ & $20,70 \pm 4,54$ & 0,425 \\
IMC $\left(\mathrm{kg} / \mathrm{m}^{2}\right)$ & 93,3 & 76,6 & 0,145 \\
Estádio de Tanner $\geq \mathrm{M2},(\%)$ & & &
\end{tabular}

IMC: Índice de massa corpórea

Dados expressos em média e desvio-padrão ou porcentagem. 
Tabela 2 - Características clínicas das pacientes com Artrite Idiopática Juvenil poliarticular (AIJp).

\section{AIJp}

$(n=30)$

Tempo de doença (meses)

$48,73 \pm 41,24$

Classe funcional (Steinbrocker)

$1,7 \pm 0,75$

CHAQ

$1,46 \pm 0,87$

DAS

$4,71 \pm 1,24$

Escala visual de dor (0-100)

$56,0 \pm 19,40$

Rigidez matinal (minutos)

$24,50 \pm 17,14$

Articulações ativas (n)

$20,76 \pm 11,73$

Articulações acometidas ( $n$ )

$21,27 \pm 11,96$

Dados expressos em média e desvio-padrão

Em relação à avaliação radiológica, todos os pacientes (100\%) apresentaram anormalidades em pelo menos uma das articulações radiografadas. Dentre as anormalidades mais freqüentes encontramos o edema de partes moles em 93,3\% dos pacientes com AIJp, osteopenia periarticular em $90 \%$, diminuição do espaço em $60 \%$ e erosões ósseas periarticulares em $40 \%$ (Tabela 3). 
Tabela 3 - Avaliação das anormalidades radiológicas presentes em pelo menos uma das articulações radiografadas

\section{AIJp}

$(n=30)$

Edema de partes moles (\%)

93,3

Osteopenia periarticular (\%)

90

Diminuição do espaço articular (\%)

60

Erosão óssea periarticular (\%)

40

Dados expressos em porcentagem.

Em relação ao sistema RANKL/RANK/OPG, observou-se altos valores de RANKL e baixa taxa de OPG/RANKL em pacientes com AIJp em atividade comparadas com controles $[2,90(0,1-37,4)$ vs. $0,25(0,1-5,7) \mathrm{pg} / \mathrm{ml}$, $\mathrm{p}=0,007$ e $21,25(1,8-897,6) \quad$ vs. $347,5(9-947,8) \mathrm{pg} / \mathrm{ml}, \mathrm{p}=0,005]$. Diferentemente, não houve diferença em relação à concentração sérica de OPG quando se comparou os dois grupos $[55,24(28,34-89,76)$ vs. 64,42 $(30,68-111,28) \mathrm{pg} / \mathrm{ml}, \mathrm{p}=0,255]$ (Tabela 4; Figuras 1 e 2).

Altos valores séricos de RANKL e baixa taxa de OPG/RANKL foi também observada em pacientes com AIJp em atividade com erosões ósseas comparadas com controles $[3,49(0,1-37,4)$ vs. $0,25(0,1-5,7) \mathrm{pg} / \mathrm{ml}$, $\mathrm{p}=0,0115$ e $14,3(1,8-897,6)$ vs. $347,5(9-947,8), \mathrm{p}=0,016]$ (Figura 1 e 2$)$. Em contraste, as concentrações séricas de RANKL e a taxa de OPG/RANKL foram semelhantes em pacientes com AIJp sem erosões ósseas e controles 
$[1,75(0,1-10,9)$ vs. $0,25(0,1-5,7) \mathrm{pg} / \mathrm{ml}, \mathrm{p}=0,055$ e $29,2(3,3-756,8)$ vs. $347,5(9-947,8), p=0,281]$ (Figura 1 e 2). No entanto, a aparente maior concentração sérica de RANKL e menor taxa de OPG/RANKL em pacientes com AIJp com erosões comparadas com aquelas sem esta complicação não atingiu significância estatística $(p>0,05)$.

Nenhuma diferença foi encontrada entre pacientes com e sem erosões ósseas em relação à duração de doença e parâmetros clínicos incluindo: CHAQ, classe funcional, DAS, número de articulações afetadas, número de articulações ativas e velocidade de hemossedimentação ( $p>0.05)$.

Tabela 4 - Parâmetros laboratoriais do metabolismo ósseo: RANKL, OPG, OPG/RANKL em pacientes com AIJp em atividade e controles.

\begin{tabular}{lccc}
\hline & AIJp & Controles & $P$ \\
& $(\mathrm{n}=30)$ & $(\mathrm{n}=30)$ & \\
\hline RANKL $(\mathrm{pg} / \mathrm{ml})$ & $2,9(0,1-37,4)$ & $0,3(0,1-5,7)$ & 0,007 \\
OPG $(\mathrm{pg} / \mathrm{ml})$ & $55,24(28,34-89,76)$ & $64,42(30,68-111,28)$ & 0,255 \\
OPG/RANKL & $21,25(1,8-897,6)$ & $347,5(9-947,8)$ & 0,005
\end{tabular}

Dados expressos em mediana. 


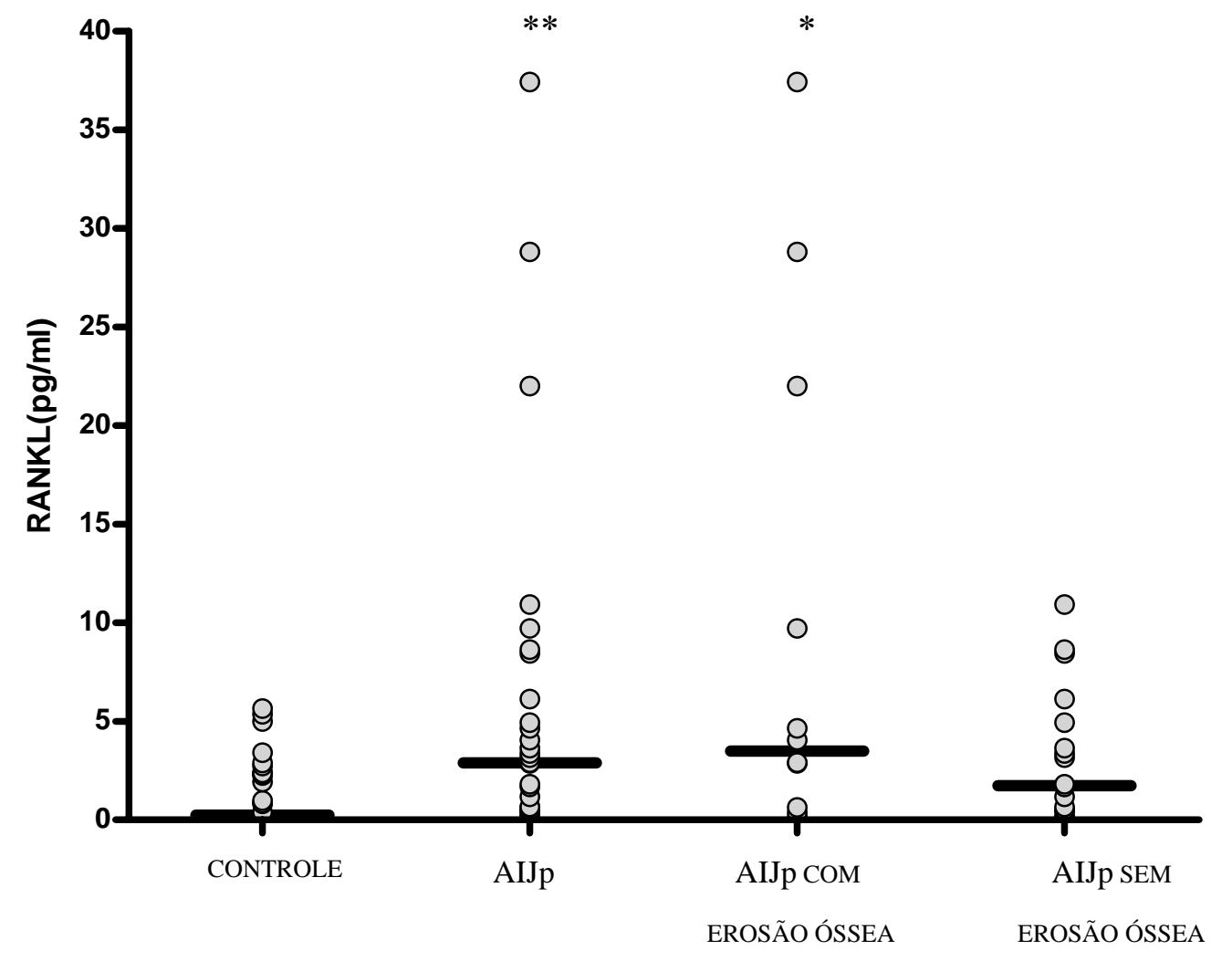

Figura 1: Valores séricos de RANKL em controles saudáveis, pacientes com AIJp, AIJp com erosões ósseas e AIJp sem erosões ósseas. Quando comparados com controles todos os pacientes com AIJp e pacientes com AIJp com erosões ósseas apresentaram maiores valores de RANKL (** $\mathrm{p}<0,01 ; * \mathrm{p}<0,05)$. 


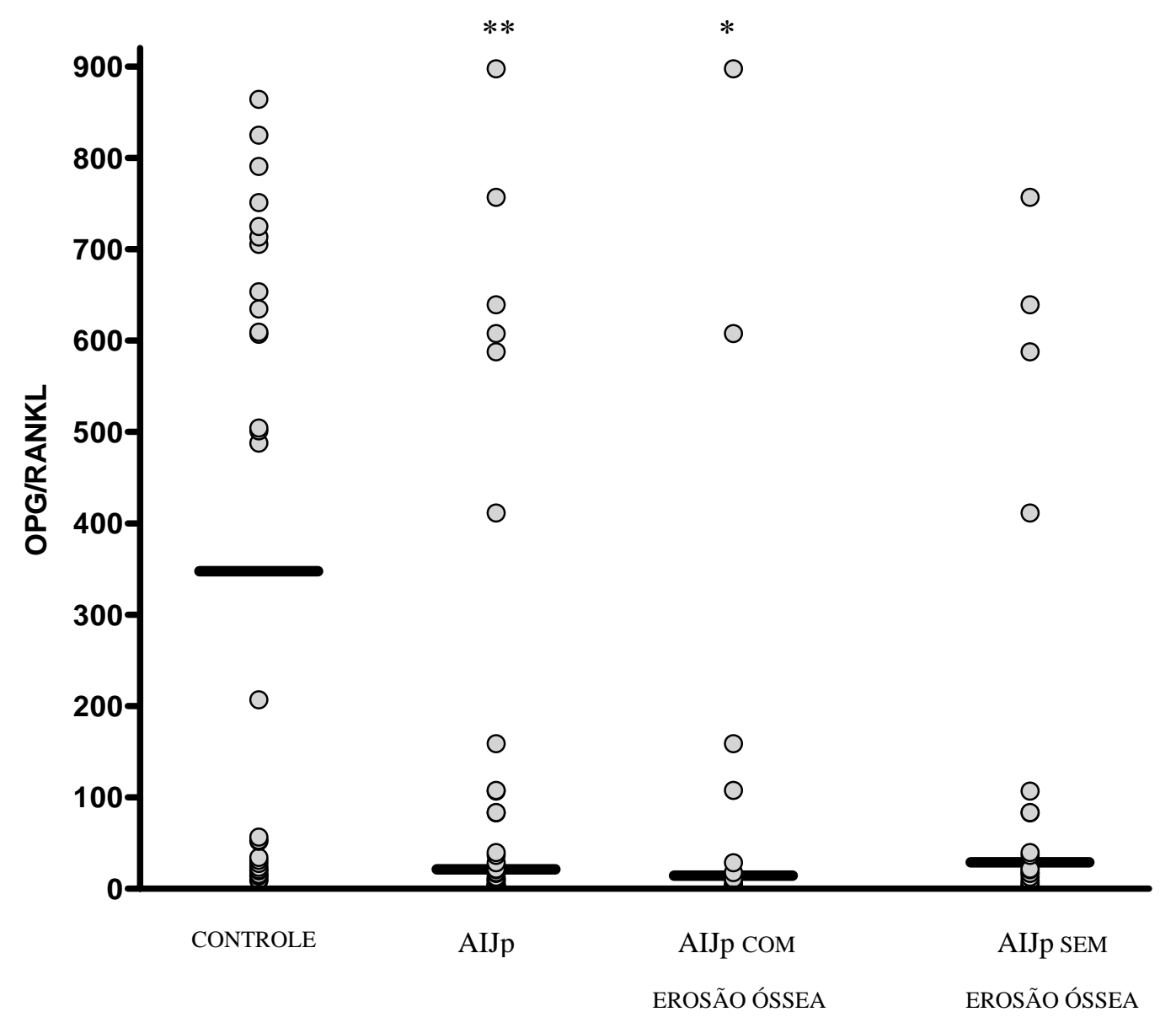

Figura 2: OPG/RANKL em controles saudáveis, pacientes com AIJp, AIJp com erosões ósseas e AIJp sem erosões ósseas. Quando comparados com controles todos os pacientes com AIJp e pacientes com AIJp com erosões ósseas apresentaram menores valores de OPG/RANKL $(* * \mathrm{p}<0,01 ; *$ $p<0,05)$ 
5. DISCUSSÃO 
No presente estudo, encontramos altos valores de RANKL e baixa taxa de OPG/RANKL no soro de pacientes com AIJ de início poliarticular em atividade, particularmente naqueles com erosões ósseas.

O RANKL é um fator crítico para diferenciação, ativação e sobrevida dos osteoclastos, células responsáveis pela reabsorção óssea (Theill et al, 2002). No micro-ambiente ósseo, o RANKL é produzido por células da linhagem osteoblástica e sua expressão é induzida por citocinas próinflamatórias, incluindo fator de necrose tumoral (TNF $\alpha$ ), IL-1 (Walsh et al, 2003). Além disso, o tecido sinovial é uma importante fonte de RANKL, influenciando a osteoclastogênese. Fibroblastos sinoviais e linfócitos T de pacientes com Artrite reumatóide expressam RNA mensageiro e produzem RANKL proteínas (Gravallese et al, 2000; Romas et al, 2000).

A AIJ é uma doença heterogênea com vários subtipos de envolvimento que variam no perfil clínico, gravidade do acometimento articular e prognóstico evolutivo (incapacidade física, lesão radiológica e remissão de doença). A grande vantagem deste trabalho é a seleção de um grupo homogêneo de pacientes com AIJ em relação ao subtipo de envolvimento articular inicial. Desta maneira, escolhemos estudar a AIJ tipo poliarticular, uma vez que este subtipo de doença é o mais agressivo em relação à destruição óssea periarticular (Adib et al, 2005), reforçando a 
possibilidade do papel modulador do sistema OPG/RANK/RANKL na lesão óssea.

Adicionalmente, é essencial para a interpretação de dados do RANKL e OPG, uma homogenização da população em relação ao sexo e estadio puberal; uma vez que os hormônios sexuais têm um efeito modulatório na interação biológica da OPG, RANKL e matriz óssea (Stern et al, 2007). No presente trabalho, a inclusão de pacientes somente do sexo feminino e púberes, contrasta com uma população exclusivamente pré-pubere em estudo prévio (Masi et al,2004), podendo explicar em parte os diferentes achados.

Além disso, níveis de RANKL e OPG alteram com a idade, com diminuição de aproximadamente $13 \%$ a cada cinco anos em adultos (Kerschan-Schin et al, 2007), e pode também ser fator de confusão na comparação dos diferentes estudos (Masi et al, 2004; Sarma et al,2007). Na nossa casuística o máximo da idade foi de 17 anos, diferente de outro estudo na literatura onde a população estudada variou de 5 a 32 anos (Sarma et al, 2007).

Em nossa amostra de pacientes também tivemos o cuidado de excluir pacientes que faziam uso de glicocorticóides até um mês antes do início do estudo. Estes esteróides têm efeito importante sobre o osso, diminuindo a formação óssea (Pereira et al, 2001) e aumentando a reabsorção óssea. Os glicocorticóides estimulam a osteoclastogênese decorrente do aumento da expressão de RANKL e redução da expressão da OPG (Canalis E, 2005). 
O presente estudo confirmou achado recente de Sarma et al mostrando elevada concentração sérica de RANKL, menor taxa de OPG/RANKL e valores semelhantes de OPG na AIJ poliarticular comparada com controles saudáveis (Sarma et al, 2007). A atividade de doença moderada a alta em todos os nossos pacientes explicaria este achado, desde que citocinas pró-inflamatórias estimulam o aumento da expressão do RANKL em osteoblastos, linfócitos T-ativados e células sinoviais ativadas (Boyle et al,2003; Wash et al, 2003). A maioria dos fatores osteoclastogênicos presente nas articulações inflamadas cronicamente (ex: IL-1, IL-6/receptor solúvel, IL-11, IL-17, PTHrP, TNF- $\alpha$ ) parecem agir indiretamente através de receptores específicos em células estromais-osteoblásticas facilitando a expressão de RANKL.

O achado de concentrações séricas elevadas de RANKL e baixa taxa de OPG/RANKL em pacientes com erosões ósseas sugerem um inadequado mecanismo compensatório no balanço do aumento do RANKL (Boyle et al, 2003; Bezerra et al, 2005). O RANKL poderia ser um fator essencial na lesão óssea independentemente do processo inflamatório. De fato, no presente trabalho, pacientes com e sem erosões ósseas tinham semelhantes o tempo de doença, os parâmetros clínicos e laboratoriais e classes funcionais, os quais não poderiam ser responsáveis por esta diferença. Esta possibilidade é suportada por estudos experimentais de camundongos artríticos com knockout de RANKL, nos quais o grau de erosão óssea é relativamente reduzido comparado com camundongos artríticos controles (Petit et al, 
2001). Além disso, estudos experimentais utilizando um modelo de artrite induzida por adjuvante mostraram que a terapia combinada com o receptor solúvel do TNF ou IL-1ra e com OPG podem ter efeito benéfico adicional não somente prevenindo o processo inflamatório mas também na lesão ósteoarticular (Zwerina et al, 2004). 
6. CONCLUSÃO 
Em conclusão, o presente estudo sugere que uma inadequada modulação do sistema OPG/RANK/RANKL em pacientes com AIJp em atividade pode ser responsável pela lesão óssea nesta doença. Estudos posteriores são necessários para determinar se a concentração sérica de RANKL ou taxa de OPG/RANKL podem ser um marcador importante da lesão óssea que ocorre nestes pacientes. 
7. ANEXOS 
ANEXO 1 - ARTI GO ORI GI NAL

OSTEOPROTEGERIN/RANKL SYSTEM IMBALANCE IN ACTIVE POLYARTICULAR-ONSET JUVENI LE IDIOPATHIC ARTHRITIS: A BONE DAMAGE BI OMARKER?

Paulo Spelling ${ }^{1}$, Eloisa Bonfá2 ${ }^{2}$ Valeria de Falco Caparbo ${ }^{2}$, Rosa Maria Rodrigues Pereira ${ }^{2}$

Rheumatology Division (Bone Mineral Metabolism Laboratory), University of São Paulo, São Paulo ${ }^{2}$ and Pediatric Rheumatology Division of Evangelical Hospital of Curitiba, Evangelical University of Curitiba, Paraná1, Brazil.

Address reprints requests and correspondence to:

Rosa Maria Rodrigues Pereira

Disciplina de Reumatologia, Faculdade de Medicina da Universidade de São Paulo

Av. Dr Arnaldo, 455- 3o andar- Reumatologia, sala 3107, São Paulo, SP, Brazil, CEP-01246-903

Phone: 5511-30617213, 5511-30617490

FAX: 55 11-30617490

E-mail: rosamariarp@yahoo.com 


\section{ABSTRACT}

Objective: To evaluate the importance of RANK/RANKL/OPG modulation in active polyarticular Juvenile Idiopathic Arthritis (pJIA) patients with and without bone erosions. Methods: Thirty female girls with active pJIA and 30 healthy children gender and age-matched controls were consecutively selected for this study. All involved articulations were assessed by X-ray and examined for the presence of bone erosions. The serum levels of RANKL and OPG were measured using an enzyme-linked immunosorbent. Results: Patients with active pJIA had higher levels of serum RANKL and lower OPG/RANKL ratio compared to controls $[2.90(0.1-37.4)$ vs. 0.25 (0.1-5.7) $\mathrm{pg} / \mathrm{ml}, \mathrm{p}=0.007]$ and $21.25(1.8-897.6)$ vs. $347.5(9-947.8) \mathrm{pg} / \mathrm{ml}, \mathrm{p}=0.005]$. However, levels of OPG were comparable in both groups [55.24 (28.3489.76) vs. $64.42(30.68-111.28) \mathrm{pg} / \mathrm{ml}, \mathrm{p}=0.255]$. Higher levels of serum RANKL and lower OPG/RANKL ratio was also observed in active pJIA patients with bone erosions compared to controls [3.49 (0.1-37.4) vs. 0.25 (0.1-5.7) $\mathrm{pg} / \mathrm{ml}, \mathrm{p}=0.0115$ and $14.3(1.8-897.6)$ vs. 347.5 (9-947.8), $\mathrm{p}=0.016]$. In contrast, RANKL levels and OPG/RANKL ratio were alike in pJIA patients without bone erosion and controls [1.75 (0.1-10.9) vs. $0.25(0.1-5.7) \mathrm{pg} / \mathrm{ml}$, $p=0.055$ and $29.2(3.3-756.8)$ vs. $347.5(9-947.8), p=0.281]$. Conclusion: These data suggest that active pJIA with bone erosions is associated with high serum levels of RANKL and low OPG/RANKL ratio indicating that these alterations may reflect bone damage in this disease. 
Key Words: Juvenile idiopathic arthritis, Osteoprotegerin, RANKL, bone erosion, polyarticular subtype

Run title: Osteoprotegerin/RANKL system in active polyarticular juvenile idiopathic arthritis 


\section{NTRODUCTI ON}

Among the articular pathologies, juvenile idiopathic arthritis (JIA) is one of the most frequent, occurring in childhood. The polyarticular subtype is the second in frequency, encompassing approximately one third of JIA patients (1). The arthritis is generally symmetric, affecting small and large joints, in addition to cervical spine and temporomandibular joints $(2,3)$. Bone erosion and articular destruction are common in polyarticular subtype and can result in severe articular incapacity requiring prosthesis (4).

Over the last decade, the tumor necrosis factor (TNF) was identified as the main inflammatory pathogenic mediator for chronic arthritis, not only inducing but also perpetuating the inflammatory process in the synovial membrane (5).

Among TNF family, receptor activator of nuclear factor kB ligand (RANKL), receptor activator of nuclear factor $k B$ (RANK) and osteoprotegerin (OPG) a soluble receptor that inactivates RANKL (6) are known to interfere in the immune system, bone metabolism and endocrine functions.

RANKL is produced by osteoblastic lineage cells, $T$ lymphocytes and synoviocytes; it stimulates the receptor RANK present in dendritic cells and osteoclasts, besides increasing survival and immune activation of dendritic cells. Osteoprotegerin, a soluble protein synthesized by osteoblasts, acts as a soluble receptor that binds to RANKL preventing the binding to RANK with a consequent decrease in osteoclast activation and function $(6,7)$. 
The RANKL/RANK/OPG system is involved in many immunologic and skeletal diseases characterized by bone resorption including postmenopausal osteoporosis, bone metastasis, periodontal disease and inflammatory arthritis $(8,9)$. In fact, others and we have demonstrated that chronic inflammatory process result in generalized bone-mass loss, bone demineralization and progressive radiological abnormalities (10-12). The bone articular complications consist of juxtarticular osteopenia, subchondrous and marginal bone erosions.

Reinforcing these findings, RANKL mRNA and protein is expressed and produced by synovial fibroblasts and activated $\mathrm{T}$ lymphocytes in arthritic joints of rats with adjuvant arthritis (AA). This experimental arthritis is characterized by bone loss and joint destruction due to abnormally increased bone resorption reflecting increased osteoclast numbers. Moreover, activated CD4+ and CD8+ $T$ cells express biologically active soluble and membranebound forms of RANKL (13).

Remarkably, treatment of animals with adjuvant arthritis with recombinant OPG protects against the development of bone and cartilage destruction. This bone-sparing effect occurred even though OPG treatment had no impact on synovial inflammation (13). These data suggest that RANKL is essential for osteoclastogenesis and therefore may modulate bone resorption independently of the inflammatory process. 
In this study, we have evaluated polyarticular JIA patients uniformly active (to homogenize this inflammatory confounding variable) with and without bone erosion, in order to understand the relevance of RANK/RANKL/OPG modulation in bone damage.

\section{SUBJ ECTS AND METHODS}

\section{Patients}

Thirty female patients with polyarticular-onset JIA, according to the ILAR criteria (14) were consecutively selected for the study. The main inclusion criteria was active disease defined by a disease activity score (DAS) greater than 2.4 (15). All patients were followed in the Pediatric Rheumatology Division of the Evangelical Hospital of Curitiba, Evangelical University of Paraná, Brazil.

Thirty healthy gender, age and socio-economic level -matched children were recruited as controls.

Secondary causes of low bone mass were excluded in patients and controls, such as a clinical history of rickets, hypoparathyroidism, poor gastrointestinal absorption, renal or hepatic insufficiency, hyperthyroidism or hypothyroidism, glucocorticoid use (last month before sera collection). 


\section{Data collection}

Demographic and anthropometric data for patients and controls were obtained through interview and physical examination, where variables collected were: age in years, weight in kilograms, height in centimeters and Tanner`s pubertal stage (breast and pubic hair) (16), age of menarche in years.

Clinical data including disease duration, articular disease involvement and activity, disease incapacity, previous use of glucocorticoid and current/previous use of methotrexate were obtained through interview, physical examination and chart review.

\section{Articular involvement and Disease Active Score (DAS)}

The overall articular involvement was defined as the sum of affect joints (tender or swollen or limited mobility). The number of active joints was defined as the presence of swelling or LOM, in addition to either pain upon movement or tenderness (17).

Composite disease activity was measured by disease activity score (DAS) (15); a score greater than 2.4 was taken as indicative of active disease.

\section{Evaluation of functional class and quality of life}

All JIA patients were evaluated for functional class by Steinbrocker criteria (18) and the functional ability assessment by CHAQ (Childhood 
Healthy Questionnaire) (19). The CHAQ analyzes the current condition of the patient as reported by himself or by his caretaker.

\section{Radiological evaluation}

Conventional film screen radiographs of all affected joints (either tender, painful, swollen, or limited in motion as judged by the pediatric rheumatologist) were obtained.

The following features were evaluated: soft-tissue swelling, juxtarticular osteopenia, joint-space narrowing, bone erosions, and all of them were scored as absent or present $(12,17)$.

High-intensity light was used to assess soft-tissue swelling, and this was scored as present if a reflection of soft-tissue swelling was found around a joint. Subchondral osteopenia was defined as present when a localized decrease of bone density was noticed around a joint. Bone erosions were defined as a discrete interruption of the cortical surface of the bone.

The final joint $x$-ray evaluation was obtained by the concordance of two physicians who are experts in the osteo-articular system.

\section{Laboratory examinations}

1. Osteoprotegerin and RANKL

Serum for the determination of ligand receptor activator of nuclear factor $\kappa B($ RANKL) and osteoprotegerin (OPG) were collected from patients and controls after fasting and stored at $-80^{\circ} \mathrm{C}$ for later measurement. 
Serum levels of uncomplexed (free) RANKL were measured by enzyme immunoassay (Biomedica) according to the manufacturer's instructions. In a first step, samples and the biotinylated polyclonal anti-RANKL detection antibody are pipetted into the wells. Human RANKL, if present in the sample, binds to recombinant OPG and forms a sandwich with the detection antibody. Tetramethybenzidine is then added to the reaction as substrate. The intraassay and inter-assay coefficient of variation were $11.8 \%$ and $19.4 \%$, respectively. (20).

Serum OPG was assayed by ELISA (Biomedica, Vienna, Austria) which uses a monoclonal anti-OPG antibody to capture OPG from serum, according to manufacturer instructions. The captured OPG is then detected with a biotinylated polyclonal anti-OPG antibody using tetramethylbenzidine as substrate. The intra-assay coefficient of variation was $5.2 \%$ and the interassay coefficient of variation was $15.5 \%$ (20).

2. Erythrocyte sedimentation rate and rheumatoid factor

The erythrocyte sedimentation rate (ESR) and rheumatoid factor (RF) determinations were analyzed for all patients. The ESR level was considered elevated above $20 \mathrm{~mm}$ in the first hour and the RF above $40 \mathrm{U}$.

Participants, or guardians for minors, signed a free-informed consent form, and the study was approved by the Ethics Committee of the University Hospital. 


\section{Statistical analysis}

Data are reported as mean and SD, median and per cent. Anthropometric and demographic variables were compared between patients and controls using the Student t-test. The variables Tanner stage $\geq \mathrm{B} 2$, weight $<25$ percentile, height $<25$ percentile were compared in patients and controls using Fischer`s exact test. Laboratorial parameters, including RANKL and OPG, were compared between JIA patients and controls, and in patients with or without erosions on the x-ray using or the Mann-Whitney Utest. All the analysis was done using SPSS Windows, version 11.0 (SSPC, Chicago, IL). P values $<0.05$ were considered to be significant.

\section{RESULTS}

Anthropometric and demographic characteristics of patients and controls are shown in table 1 . Mean age of patients and controls was 11.07 years $(p=1.00)$ with a range of $4-17$ years old. No difference between patients and controls was observed in anthropometric data for weight and height ( $p>0.05)$, although $40 \%$ of JIA patients were below 25 percentile of weight compared to $10 \%$ in the control group $(p=0.015)$. Similarly, $93.3 \%$ of JIA patients and $33.3 \%$ of control group were below the 25 percentile of height $(p<0.0001)$. Concerning Tanner puberty stage, $93.3 \%$ of JIA patients and $76.6 \%$ of control group were puberal (presenting stages B2P2, B3P3, B4P4, B5P5) $(p=0.145)$. 
Mean disease duration was $48.73 \pm 41.24$ months and Steinbrocker functional class was $1.7 \pm 0.75$. The mean of functional capacity scores (CHAQ) was $1.46 \pm 0.87$ and the mean DAS was $4.71 \pm 1.24$. Morning stiffness ranged from 0 to 60 minutes with a mean of $24.50 \pm 17.14$ minutes and the visual analog scale for pain had a mean of $56.0 \pm 19.40$. The mean number of affected joints was $21.27 \pm 11.96$ (range from 5 to 55 joints), and the active joint count was $20.76 \pm 11.73$ (Table 2).

Eighty-three percent of JIA patients were using methotrexate, $73.3 \%$ non-steroidal anti-inflammatory drugs (NSAIDs) and 6.6\% azathioprine at the moment of the study.

Rheumatoid factor was positive in only $10 \%$ of JIA patients and the ESR was $44.47 \pm 27.53 \mathrm{~mm}$ in the first hour. All patients (100\%) had radiologic abnormalities in at least one of their radiographed joints. The most frequent abnormality was soft-tissue swelling (93.3\%), juxtarticular osteopenia was observed in $90 \%$, joint-space narrowing in $60 \%$ and bone erosions in $40 \%$ of JIA patients (Table 3 ).

With regard to RANKL/RANK/OPG system, higher levels of RANKL and lower OPG/RANKL ratio were found in pJIA patients compared to controls [2.90 (0.1-37.4) vs. $0.25(0.1-5.7) \mathrm{pg} / \mathrm{ml}, \mathrm{p}=0.007$ and $21.25(1.8-897.6) v s$. 347.5 (9-947.8) $\mathrm{pg} / \mathrm{ml}, \mathrm{p}=0.005]$. However, levels of OPG were comparable in both groups [55.24 (28.34-89.76) vs. $64.42(30.68-111.28)] \mathrm{pg} / \mathrm{ml}$, $\mathrm{p}=0.255]$ (Table 4, Figure 1 and 2). 
Higher levels of serum RANKL and lower OPG/RANKL ratio was also observed in active pJIA patients with bone erosions compared to controls [3.49 (0.1-37.4) vs. $0.25(0.1-5.7) \mathrm{pg} / \mathrm{ml}, \mathrm{p}=0.0115$ and $14.3(1.8-897.6)$ vs. 347.5 (9-947.8), $\mathrm{p}=0.016]$ (Figure 1 and 2). In contrast, RANKL levels and OPG/RANKL ratio were alike in pJIA patients without bone erosion and controls [1.75 (0.1-10.9) vs. $0.25(0.1-5.7) \mathrm{pg} / \mathrm{ml}, \mathrm{p}=0.055$ and 29.2 (3.3756.8) vs. $347.5(9-947.8), p=0.281]$ (Figure 1 and 2). In spite of that, the apparent higher levels of serum RANKL and lower OPG/RANKL ratio in pJIA with bone erosions compared to those without this complication did not reach statistical significance $(p>0.05)$.

No difference was found between patients with and without bone erosions concerning disease duration and clinical parameters including: $\mathrm{CHAQ}$, functional class, DAS, number of affected joints, number of active joints and erythrocyte sedimentation rate $(p>0.05)$.

\section{DISCUSSION}

The present study has shown high levels of RANKL and low OPG/RANKL ratio in sera of active polyarticular-onset JIA girls, particularly in those with bone damage.

The RANKL is a critical factor for differentiation, activation and prolonged survival of osteoclasts, cells responsible for bone resorption (21). In the bone microenvironment RANKL is produced by osteoblastic lineage 
cells and its expression is induced by pro-inflammatory cytokines (22). In addition, the synovial tissue is also an important source of RANKL inducing osteoclastogenesis. Synovial fibroblasts and T lymphocytes in rheumatoid arthritis patients express mRNA and produce proteins for RANKL $(23,24)$.

JIA is a heterogenous disorder comprising several disease subtypes that varies in the pattern and severity of joint involvement and outcomes (disability, radiological damage and remission). We therefore chose to study herein the polyarticular JIA since it is the most aggressive subtype of disease with regard to bone erosions and disability (4) reinforcing the possibility of a modulating role for OPG/RANK/RANKL system in bone damage. The great advantage of this work is the homogenous selection of JIA group with regard to subtype of articular onset involvement.

In addition, it is essential for RANKL and OPG data interpretation a homogeneous gender and puberal status population, since sex-hormones have a modulatory effect on biologic interaction of OPG, RANKL and bone (25). The inclusion of solely female and predominant puberal subjects in the present work contrasts with an exclusive prepuberal population in previous report (26) and might explain in part the discrepant results. Furthermore, RANKL and OPG levels change with age, with a decrease of approximately $13 \%$ every five years (27) and may also hamper the comparison of different studies $(26,28)$.

Moreover, in our study all patients using glucocorticoid up to one month before the study entry were excluded. Steroids have an important 
effect in bone cells, decreasing bone formation (29) and increasing bone resorption. The glucocorticoids increase osteoclastogenesis due to increased expression of RANKL and reduced expression of OPG (30).

We have confirmed recently observation of Sarma et al., 2007 of elevated serum levels of RANKL and lower OPG/RANKL ratio and comparable levels of OPG in polyarticular subtype compared to healthy controls (28). The uniform moderate to high disease activity in our patients is the most likely explanation for this finding, since pro-inflammatory cytokines is known to stimulate an increase of RANKL expression in osteoblast, activated Tlymphocytes and activated synovial cells $(31,22)$. Most of the osteoclastogenic factors present in chronic inflammatory arthritis joints (eg, IL-1, IL-6/soluble receptor, IL-11, Il-17, PTHrP, TNF- $\alpha$ ) are thought to function indirectly via specific receptors on stromal-osteoblastic cells to enhance RANKL expression.

Remarkably, the finding of high levels of RANKL and low OPG/RANKL ratio in JIA patients with bone erosions suggest an inadequate compensatory mechanism to balance the increase of RANKL $(9,31)$. We hypothesize that RANKL could be therefore an essential factor for bone damage independently of the inflammatory process. In fact, patients with and without erosions evaluated herein had similar disease duration, clinical, functional and laboratorial parameters that could not account for this difference. This possibility is supported by experimental studies of arthritic RANKL knockout mice in which the degree of bone erosion is dramatically reduced compared 
with that seen in arthritic control mice (32). Moreover, studies using adjuvant arthritis model provide evidence that combined therapy of soluble TNF receptor or IL-1ra with OPG may have additional beneficial effect not only preventing the inflammatory process but also in bone and cartilage loss (33).

In conclusion the present study suggests an ineffective modulation of OPG/RANK/RANKL system in active pJIA which may account for bone damage in this disease. Further studies are necessary to determine if RANKL serum levels or OPG/RANKL ratio will be a valuable biomarker for bone injury in these patients.

\section{REFERENCES:}

1. Cassidy JT. Juvenile rheumatoid arthritis. Cassidy JT \& Petty RE. Textbook of Pediatric Rheumatology. $4^{\text {rd }}$ ed. W.B.Saunders Company USA, 2001 pg 133-219.

2. Brewer EJ Jr, Bass J, Baum J, et al. Current proposed revision of JRA Criteria. JRA Criteria Subcommitee of Diagnostic and Therapeutic Criteria of the American Rheumatism Section of the Arthritis Foundation. Arthritis Rheum 1997;20:195-9. 
3. Ronchezel MV, Hilario MO, Goldenberg J, et al. Temporomandibular joint and mandibular growth alterations in patients with juvenile rheumatoid arthritis. J Rheumatol 1995;22:1956-61.

4. Adib N, Silman A, Thomson W. Outcome following onset of juvenile idiopathic inflammatory arthritis: II. Predictors of outcome in juvenile arthritis. Rheumatology 2005;44:1002-7.

5. Vervoordeldonk MJ, Tak PP. Cytokines in rheumatoid arthritis. Curr Rheumatol Rep 2002;4:208-17.

6. Hofbauer LC, Heufelder AE. Role of receptor activator of nuclear factor- KB ligand and osteoprotegerin in bone cell biology. J Mol Méd 2001;79:243-53.

7. Bezerra MC, Carvalho JF, Prokopowitsch AS, Pereira RM. RANK, RANKL and osteoprotegerin in arthritic bone loss. Braz J Med Biol Res 2005;38:16170.

8. Lerner UH. New molecules in the tumor necrosis factor ligand and receptor superfamilies with importance for physiological and pathologic bone resorption. Crit Rev Oral Biol Med 2004;15:64-81. 
9. Teng $Y T$, Nguyen $H$, Gao $X$, Kong $Y Y$, et al. Functional human T-cell immunity and osteoprotegerin ligand control alveolar bone destruction in periodontal infection. J Clin Invest 2000; 106:59-67.

10. Pereira RM, Corrente JE, Chahade WH, Yoshinari NH. Evaluation by dual X-ray absorptiometry (DXA) of bone mineral density in children with juvenile chronic arthritis. Clin Exp Rheumatol 1998;16:495-501.

11. Reed MH, Wilmot DM. The radiology of juvenile rheumatoid arthritis. A review of the English language literature. J Rheumatol 1991;18(suppl 31):222.

12. Mason T, Reed AM, Nelson AM, et al. Frequency of abnormal hand and wrist radiographs at time of diagnosis of polyarticular juvenile rheumatoid arthritis. J Rheumatol 2002;29:2214-18.

13. Kong Kong YY, Feige U, Sarosi I, et al. Activated $T$ cells regulate bone loss and joint destruction in adjuvant arthritis through osteoprotegerin ligand. Nature 1999;402:304-9. 
14. Petty RE, Southwood TR, Manners P, et al. International League of Associations for Rheumatology. International League of Associations for Rheumatology classification of juvenile idiopathic arthritis: second revision, Edmonton, 2001. J Rheumatol 2004;31:390-2.

15. Lurati A, Pontikaki I, Teruzzi B, et al. A comparison of response criteria to evaluate therapeutic response in patients with juvenile idiopathic arthritis treated with methotrexate and/or anti-tumor necrosis factor alpha agents. Arthritis Rheum 2006;54:1602-7.

16. Tanner JM, O'Keefe B. Age at menarche in Nigerian school girls, with a note on their heights and weights from age 12 to 19 . Hum Biol $1962 ; 34: 187-96$.

17. van Rossum MAJ, Zwinderman $A H$, Boers $M$, et al. Radiologic features in juvenile idiopathic arthritis. Arthritis Rheum 2003;48:507-15.

18. Steinbrocker O. Prognosis for employability in the major arthritides rheumatoid arthritis, osteoarthritis and gout. Pa Med 1969;72:82-5.

19. Brasil TB, Ferriani VP, Machado CS. Health related quality of life survey about children and adolescents with juvenile idiopathic arthritis. J Pediatr (Rio J) 2003;79:373; author reply 374 . 
20. Bezerra MC, Calomeni GD, Caparbo VF, Gebrim ES, Rocha MS, Pereira RM. Low bone density and low serum levels of soluble RANK ligand are associated with severe arterial calcification in patients with Takayasu arteritis. Rheumatology 2005;44:1503-6.

21. Theill LE, Boyle WJ, Penninger JM. RANKL and RANK: T cells bone loss and mammalian evolution. Annu Rev Immunol 2002;20:795-823.

22. Walsh MC, Choi X. Biology of the TRANCE axis. Cytokine Growth Factor Rev 2003;14:251-63.

23. Gravallese EM, Manning C, Tsay A, et al. Synovial tissue in rheumatoid arthritis is a source of osteoclast differentation factor. Arthritis Rheum $2000 ; 43: 250-8$

24. Romas E, Bakharevski O, Hards DK, et al. Expression of osteoclast differentation factor at sites of bone erosion in collagen-induced arthritis. Arthritis Rheum 2000;43:821-6.

25. Stern A, Laughlin GA, Bergstrom J, Barret-Connor E. The sex-specific association of serum osteoprotegerin and receptor activator of nuclear factor kappaB legend with bone mineral density in older adults: the Rancho Bernardo study. Eur J Endocrinol 2007;156:555-62. 
26. Masi L, Simonini G, Piscitelli E, et al. Osteoprotegerin (OPG)/RANK-L system in juvenile idiopathic arthritis: Is there a potential modulating role for OPG/RANK-L in bone injury? J Rheumatol 2004;31:986-91.

27. Kerschan-Schindl K, Wendlova J, Kudlacek S, Gleiss A, Woloszczuk W, Pietschmann P. Serum Levels of Receptor Activator of Nuclear Factor kappa B Ligand (RANKL) in Healthy Women and Men. Exp Clin Endocrinol Diabetes 2007; Dec 10 [Epub ahead of print]

28. Sarma PK, Misra R, Aggarwal A. Elevated serum receptor activator of NFkappa B ligand (RANKL), osteoprotegerin (OPG), matrix metalloproteinase (MMP)3, and ProMMP1 in patients with juvenile idiopathic arthritis. Clin Rheumatol 2007 Aug 17 [Epub ahead of print].

29. Pereira RM, Delany AM, Canalis E. Cortisol inhibits the differentiation and apoptose of osteoblasts in culture. Bone 2001;28:484-90.

30. Canalis E. Mechanism of glucocorticoid action in bone. Curr Osteoporos Rep 2005;3:98-102.

31. Boyle WJ, Simonet WS, Lacey DL. Osteoclast differentiation and activation. Nature 2003;423:337-42. 
32. Pettit AR, Ji $H$, von Stechow $D$, et al. TRANCE/RANKL knockout mice are protected from bone erosion in a serum transfer model of arthritis. Am J Pathol 2001;159:1689-99.

33. Zwerina J, Hayer S, Tohidast-Akrad $M$ et al. Single and combined inhibition of tumor necrosis factor, interleukin-1, and RANKL pathways in tumor necrosis factor-induced arthritis: effects on synovial inflammation, bone erosion, and cartilage destruction. Arthritis Rheum 2004; 50:277-90. 
Table 1 - Demographic and antrophometric characteristics in patients with polyarticular Juvenile Idiopathic Arthritis (pJIA) and healthy controls.

\begin{tabular}{lccc}
\hline & $\begin{array}{c}\text { pJIA } \\
(\mathrm{n}=30)\end{array}$ & $\begin{array}{c}\text { Healthy controls } \\
(\mathrm{n}=30)\end{array}$ & $\mathrm{P}$ \\
\hline Age (years) & $11.07 \pm 3.77$ & $11.07 \pm 3.77$ & 1.00 \\
Weight $(\mathrm{kg})$ & $36.7 \pm 12.39$ & $43.75 \pm 16.82$ & 0.07 \\
Weight $<25$ percentile, & 40 & 10 & 0.015 \\
$(\%)$ & & & \\
Height $(\mathrm{cm})$ & $1.33 \pm 0.17$ & $1.43 \pm 0.18$ & 0.06 \\
Height $<25$ percentile, (\%) & 93.3 & 33.3 & $<0.0001$ \\
BMI $\left(\mathrm{kg} / \mathrm{m}^{2}\right)$ & $19.89 \pm 3.15$ & $20.70 \pm 4.54$ & 0.42 \\
Tanner stage $\geq$ M2, (\%) & 93.3 & 76.6 & 0.15 \\
\hline
\end{tabular}

BMI: body mass index

Table 2 - Clinical characteristics: Disease duration, Steinbrocker functional class, CHAQ, visual analog scale, morning stiffness, active joint count and the affected joints in patients with pJIA.

\begin{tabular}{lc}
\hline & $\begin{array}{c}\text { pJIA } \\
(\mathrm{n}=30)\end{array}$ \\
\hline Duration of disease (months) & $48.73 \pm 41.24$ \\
Functional class (Steinbrocker) & $1.7 \pm 0.75$ \\
CHAQ & $1.46 \pm 0.87$ \\
DAS & $4.71 \pm 1.24$ \\
Visual analog scale of pain (0-100) & $56.0 \pm 19.40$ \\
Morning stiffness (minutes) & $24.50 \pm 17.14$ \\
\# of active joints ( $n$ ) & $20.76 \pm 11.73$ \\
\# of affected joints $(n)$ & $21.27 \pm 11.96$ \\
\hline
\end{tabular}


Table 3 - Radiologic abnormalities in at least one of their radiographed joints

\begin{tabular}{lc}
\hline & $\begin{array}{c}\text { pJIA } \\
(\mathrm{n}=30)\end{array}$ \\
\hline Soft-tissue swelling (\%) & 93.3 \\
Juxtarticular osteopenia (\%) & 90 \\
Narrowing of joint space (\%) & 60 \\
Bone erosions (\%) & 40 \\
\hline
\end{tabular}

Table 4 - Laboratorial parameters of bone metabolism: RANKL, OPG, OPG/RANKL in Juvenile idiopathic patients (pJIA) and healthy controls.

\begin{tabular}{lccc}
\hline & $\begin{array}{c}\text { pJIA } \\
(\mathrm{n}=30)\end{array}$ & Healthy controls $(\mathrm{n}=30)$ & $P$ \\
\hline RANKL $(\mathrm{pg} / \mathrm{ml})$ & $2.9(0.1-37.4)$ & $0.3(0.1-5.7)$ & 0.007 \\
OPG $(\mathrm{pg} / \mathrm{ml})$ & $55.24(28.34-89.76)$ & $64.42(30.68-111.28)$ & 0.255 \\
OPG/RANKL & $21.25(1.8-897.6)$ & $347.5(9-947.8)$ & 0.005
\end{tabular}

Data expressed in median 


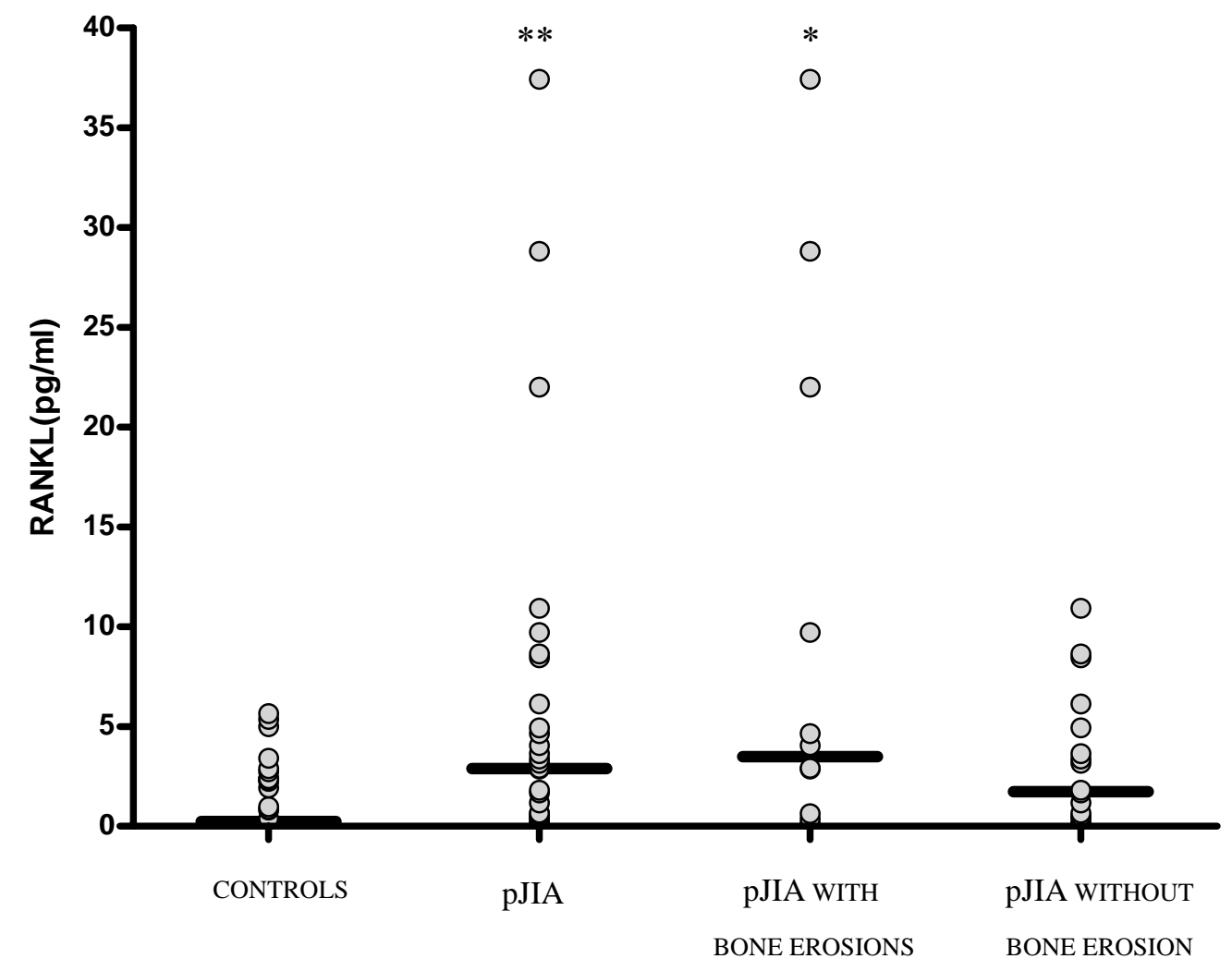

Figure 1: Scatter plot showing serum levels of RANKL in healthy controls, pJIA patients, pJIA with bone erosions and pJIA without bone erosions. As compared to controls, all pJIA patients and pJIA with bone erosions had higher levels of RANKL $(* * p<0.01 ; * p<0.05)$. 


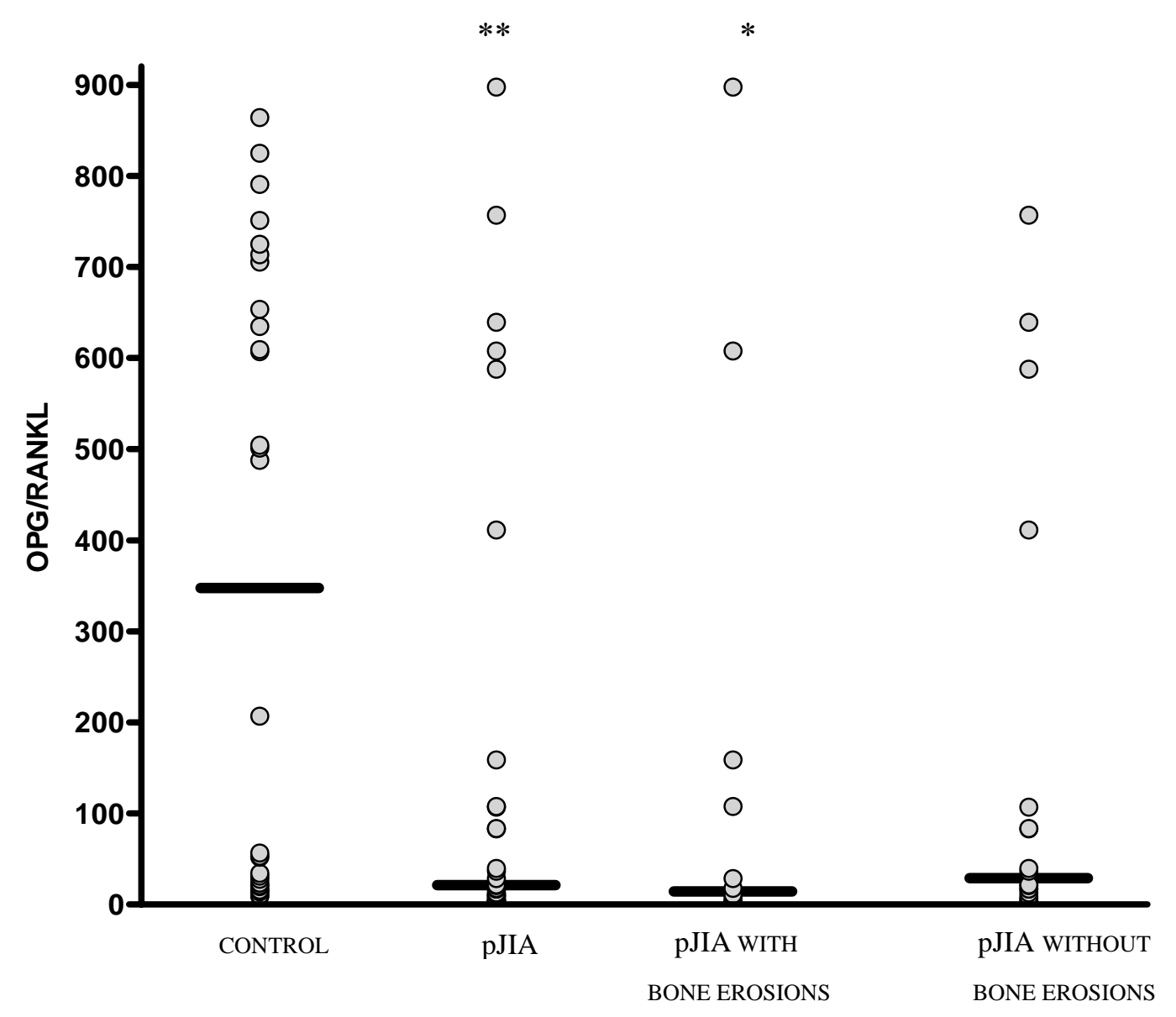

Figure 2: Scatter plot showing OPG/RANKL ratio in healthy controls, pJIA patients, pJIA with bone erosions and pJIA without bone erosions. As compared to controls, all pJIA patients and pJIA with bone erosions had lower OPG/RANKL ratio $(* * p<0.01 ; * p<0.05)$. 


\section{ANEXO 2 - APROVAÇÃo do PROJ ETO PELA COMISSÃo dE ÉTICA PARA ANÁlise de PROJetos de PESQUISA do hOSPITAL DAS CLÍ NI CAS DA FACULDADE DE MEDI CI NA DA USP}

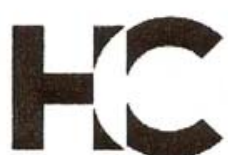

HOSPITAL DAS CLWHCAS

DA FACULDADE DE MEDICINA

\section{APROVAÇÃO}

As Comissão de Ética para Análise de Projetos de Pesquisa - CAPPesq da Diretoria Clínica do Hospital das Clínicas e da Faculdade de Medicina da Universidade de São Paulo, em sessão de 26.10.06, APROVOU ○ Protocolo de Pesquisa $n^{\circ}$ 948/06, intitulado: "Avaliação do sistema osteoprotegerina e RANKL em pacientes com artrite idiopática juvenil tipo poliarticular", apresentado pelo Departamento de Clínica Médica, inclusive Termo de Consentimento Livre e Esclarecido.

Cabe ao pesquisador elaborar e apresentar à CAPPesq, os relatórios parciais e final sobre a pesquisa (Resolução do Conselho Nacional de Saúde n 196, de 10.10.1996, inciso IX. 2, letra "c")

Pesquisador(a) Responsável: Profa. Dra. Rosa M.R.Pereira

Pesquisadores Executantes: Paulo Fernando Spelling, Valéria de Falco Caparbo

CAPPesq, 26 de Outubro de 2006.

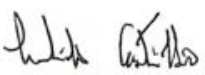

PROF. DR. EUCLIDES AYRES DE CASTILHO Presidente da Comissão de Ética para Análise de Projetos de Pesquisa Comissão de Ética para Análise de Projetos de Pesquisa do HCFMUSP e da FMUSP
Diretoria Clínica do Hospital das Clínicas da Faculdade de Medicina da Universidade de São Paulo Rua Ovídio Pires de Campos. 225, $5^{\circ}$ andar - CEP 05403010 - São Paulo - SP 


\section{ANEXO 3 - APROVAÇÃO DO PROJ ETO PELO COMITÊ EM PESQUISA DA SOCI EDADE EVANGÉLI CA BENEFI CENTE DE CURITI BA}

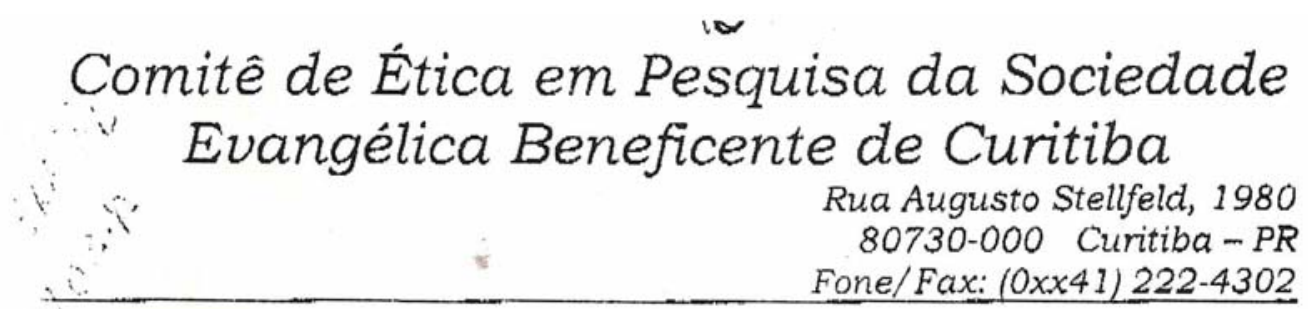

Curitiba, 16 de dezembro de 2003.

Ilimo Sr.

Dr. Paulo Fernando Spelling

HLEC.

Prezado Colega,

Através do presente, comunicamos a V. Sa. que, em reunião ordinária 16 de dezembro de 2003, foi aprovado o Protocolo de pesquisa intitulado: Dosagem de Ostcoprotegerina e Rankl em Crianças com Artrite Reumatólde Juvenil (ARJ), hem como scu respectivo Termo de Consentimento Livre e Esclarecido, protocolado ncstc comitê sob número 009/03.

Prevê a legislação que toda a documentação dos projetos poderá, a qualquer momento, ser solicitada para inspeçăo por parte dos órgàos federais; desta forma, mantera o Comitê arquivo detalhado de cada projeto, arquivando $\mathrm{cm}$ pasta individual o projeto inicial e relatórios de acompanhamonto, bem como cópias dos termos de consentimento live c usclarecido de pacientes eventualmonte envolvidos.

Para o projeto de V. Sa., solicitamos que dê ciência aos seus colaboradores da obrigaça do a cada seis meses a partir da data dc hoje, encaminhar a este comitê relatório detalhado do andamento do projeto.

Relatórios previstos para: $16 / 06 / 04$ e 16/12/04 ou até o fim do estudo no caso de se prolongar por mais de 1 ano.

Sendo o que havià para o momento, subscrevemo-nos.

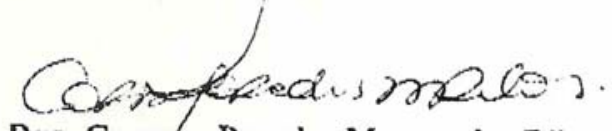

Dra. Carmen Paredes Marcondes Ribas

Coordenadora do Comitê de Ética em Pesquisa da

Sociedad'e Eraigélica Beneficente de Curitiba 
Adib N, Silman A, Thomson W. Outcome following onset of juvenile idiopath ic inflammatory arthritis: II. Predictors of outcome in juvenile arthritis. Rheumatology 2005;44:1002-1007.

Bezerra MC, Calomeni GD, Caparbo VF, Gebrim ES, Rocha MS, Pereira RM. Low bone density and low serum levels of soluble RANK ligand are associated with severe arterial calcification in patients with Takayasu arteritis. Rheumatology 2005;44:1503-1506.

Bezerra MC, Carvalho JF, Prokopowitsch AS, Pereira RM. RANK, RANKL and osteoprotegerin in arthritic bone loss. Braz J Med Biol Res. 2005;38:161-170.

Boyle WJ, Simonet WS, Lacey DL. Osteoclast differentiation and activation. Nature 2003;423:337-342.

Brasil TB, Ferriani VP, Machado CS. Health related quality of life survey about children and adolescents with juvenile idiopathic arthritis. $J$ Pediatr (Rio J) 2003;79:373; author reply 374 . 
Brewer EJ Jr, Bass J, Baum J, et al. Current proposed revision of JRA Criteria. JRA Criteria Subcommitee of Diagnostic and Therapeutic Criteria of the American Rheumatism Section of the Arthritis Foundation. Arthritis Rheum. 1997;20:195-199.

Canalis E. Mechanism of glucocorticoid action in bone. Curr Osteoporos Rep. 2005;3:98-102.

Cassidy JT. Juvenile rheumatoid arthritis. Cassidy JT \& Petty RE. Textbook of Pediatric Rheumatology. $4^{\text {rd }}$ ed. W.B.Saunders Company. USA, 2001; pg 133219.

Gravallese EM, Manning C, Tsay A, et al. Synovial tissue in rheumatoid arthritis is a source of osteoclast differentation factor. Arthritis Rheum. 2000;43:250-258.

Hofbauer LC, Heufelder AE. Role of receptor activator of nuclear factor- KB ligand and osteoprotegerin in bone cell biology. J Mol Med. 2001;9:243-253.

Kerschan-Schindl K, Wendlova J, Kudlacek S, Gleiss A, Woloszczuk W, Pietschmann P. Serum Levels of Receptor Activator of Nuclear Factor kappa B Ligand (RANKL) in Healthy Women and Men. Exp Clin Endocrinol Diabetes. 2007;Dec 10 [Epub ahead of print]. 
Kong Kong YY, Feige U, Sarosi I, et al. Activated T cells regulate bone loss and joint destruction in adjuvant arthritis through osteoprotegerin ligand. Nature. 1999;402:304-309

Lerner UH. New molecules in the tumor necrosis factor ligand and receptor superfamilies with importance for physiological and pathologic bone resorption. Crit Rev Oral Biol Med. 2004;15:64-81.

Lurati A, Pontikaki I, Teruzzi B, et al. A comparison of response criteria to evaluate therapeutic response in patients with juvenile idiopathic arthritis treated with methotrexate and/or anti-tumor necrosis factor alpha agents. Arthritis Rheum. 2006;54:1602-1607.

Masi L, Simonini G, Piscitelli E, et al. Osteoprotegerin (OPG)/RANK-L system in juvenile idiopathic arthritis: Is there a potential modulating role for OPG/RANK-L in bone injury? J Rheumatol. 2004;31:986-991.

Mason T, Reed AM, Nelson AM, et al. Frequency of abnormal hand and wrist radiographs at time of diagnosis of polyarticular juvenile rheumatoid arthritis. J Rheumatol. 2002;29:2214-2218. 
Pereira IA, Pereira RM. Osteoporose e erosões ósseas focais na artrite reumatóide: da patogênese ao tratamento. Rev Bras Reumatol. $2004 ; 445: 347-354$.

Pereira RM, Corrente JE, Chahade WH, Yoshinari NH. Evaluation by dual Xray absorptiometry (DXA) of bone mineral density in children with juvenile chronic arthritis. Clin Exp Rheumatol. 1998;16:495-501.

Pereira RM, Delany AM, Canalis E. Cortisol inhibits the diferentation and apoptose of osteoblasts in culture. Bone. 2001;28:484-490.

Pettit AR, Ji $H$, von Stechow $D$, et al. TRANCE/RANKL knockout mice are protected from bone erosion in a serum transfer model of arthritis. $\mathrm{Am} \mathrm{J}$ Pathol. 2001;159:1689-1699.

Petty RE, Southwood TR, Manners P, et I.. International League of Associations for Rheumatology. International League of Associations for Rheumatology classification of juvenile idiopathic arthritis: second revision, Edmonton, 2001. J Rheumatol. 2004;31:390-392

Reed $\mathrm{MH}$, Wilmot DM. The radiology of juvenile rheumatoid arthritis. A review of the English language literature. J Rheumatol. 1991;18(suppl 31):222. 
Romas E, Bakharevski O, Hards DK, et al. Expression of osteoclast differentation factor at sites of bone erosion in collagen-induced arthritis. Arthritis Rheum. 2000;43:821-826.

Ronchezel MV, Hilario MO, Goldenberg J et al. Temporomandibular joint and mandibular growth alterations in patients with juvenile rheumatoid arthritis. $J$ Rheumatol. 1995;22:1956-1961.

Sarma PK, Misra R, Aggarwal A. Elevated serum receptor activator of NFkappa B ligand (RANKL), osteoprotegerin (OPG), matrix metalloproteinase (MMP)3, and ProMMP1 in patients with juvenile idiopathic arthritis. Clin Rheumatol. 2007;Aug 17 [Epub ahead of print]

Steinbrocker O. Prognosis for employability in the major arthritides rheumatoid arthritis, osteoarthritis and gout. Pa Med. 1969;72:82-85.

Stern A, Laughlin GA, Bergstrom J, Barrett-Connor E. The sex-specific association of serum osteoprotegerin and receptor activator of nuclear factor kappaB legend with bone mineral density in older adults: the Rancho Bernardo study. Eur J Endocrinol. 2007; 156:555-562. 
Tanner JM, O'Keefe B. Age at menarche in Nigerian school girls, with a note on their heights and weights from age 12 to 19 . Hum Biol. 34:1962;187196.

Teng YT, Nguyen $\mathrm{H}$, Gao X, et al. Functional human T-cell immunity and osteoprotegerin ligand control alveolar bone destruction in periodontal infection. J Clin Invest. 2000; 106:59-67.

Theill LE, Boyle WJ, Penninger JM. RANKL and RANK: T cells bone loss and mammalian evolution. Annu Rev Immunol. 2002;20:795-823.

van Rossum MAJ, Zwinderman $A H$, Boers $M$, et al. Radiologic features in juvenile idiopathic arthritis. Arthritis Rheum. 2003;48:507-515.

Vervoordeldonk MJ, Tak PP. Cytokines in rheumatoid arthritis. Curr Rheumatol Rep. 2002;4:208-217.

Walsh MC, Choi X. Biology of the TRANCE axis. Cytokine Growth Factor Rev. 2003;14:251-263. 
Zwerina J, Hayer S, Tohidast-Akrad M et al. Single and combined inhibition of tumor necrosis factor, interleukin-1, and RANKL pathways in tumor necrosis factor-induced arthritis: effects on synovial inflammation, bone erosion, and cartilage destruction. Arthritis Rheum. 2004; 50:277-90. 